\title{
Über die Wirkung des Pilocarpins auf einige Fermente des Harns.
}

\author{
Von \\ Hiroyuki Yamamoto. \\ (III本贸行) \\ (Aus Prof. Kumagai's mediainischer Klinik, Tohola \\ thiversitat $\approx u$ Sendai.)
}

Bekanntlich enthült der tierische Harn verschiedene Fermente : Amylase, Trypsin, Pepsin und Iipase. Ausserdem hat der Harn diese Fermente hemmende Wirkungen, wie z. B. antitryptische und antipeptische Wirkung. Der Gehalt des Harns an diesen Fermenten ist von dem jeweiligen Zustand des Organs des Tiers abhängig, z. B. fehlt Pepsin im Harn des Individuums, dessen Magenschleimhaut nicht mehr fühig ist, Magensaft abzusondern. Die Amylase des Harns soll meist vom Pankreas stammen. Wohlgemuth und Noguchi ${ }^{13}$ konnten deshalb nachreisen, dass Harnamylase bei Unterbindung des Ductus Wirsungianus oder Verletzung des Pankreas vorübergchende Steigerung erfïhrt. Deshalb wollen diese Autoren den Amylasegehalt des Bluts und des Harns zur Diagnostizierung der Pankreaserkrankung angewendet wissen.

Achard, Clerc, ${ }^{2}$ Loeper und Fiçai" haben gefunden, dass die Blutamylase durch Pilocarpininjektion auf enorme Höhe getrieben wird. Osato ${ }^{4}$ hat diese Erscheinung weitor verfolgt und gefunden, dass die dabei gesteigerte Amylase vom Pankreas stammt. Nach ihm tritt Amylase aus dem Pankreas auf dem Wege über den Ductus thoracicus ins Blut ein. Ferner hat Osato gefunden, dass auch Trypsin durch Pilocarpin aus dem Pankreas in enormer Menge ins Blut getrieben wird. Tsunoda ${ }^{()}$ hat aber durch Pilocarpininjektion keine Steigerung der Blutamylase erzielt. Andererseits hat Masumizu $\mathrm{u}^{5)}$ gefunden, dass sowohl stomachal wie auch subkutan einverleibte Amylase zum Teil in den Harn ausgeschieden wird. 
Wir haben uns num die Frage vorgelegt, ob diese durch Pilocarpininjektion in die Höhc getricbenen Fermente im Blut in den Harn übergehen. U̇ber die hierbei gewonnenen Resultate sei im folgenden berichtet.

Methodisches: Für unsere Versuche sind hauptsächlich Kaninchen mittlerer Grösse benutzt worden; für einige Versuche aber haben wir auch Hunde verwendet. Die Injektion salzsauren Pilocarpins ist in 10 óiger lösung subkutan an Tieren ausgefihrt, die 24 Stunden gehungert hatten. Dabei bekamen die Tiere starke Vergiftungserscheinungen: Speichelaustluss, Zittern, Krïmpfe usw. Blut durch Venenpunktion entnommen, nach Stehenlasen im Eisschrank uber eine Nacht lang abzentrifugiert; Urin mittels feinen Katbeters kontinuierlich entnommen und rerurbeitet.

\section{Amylase.}

Da weder Blut noch auch Urin hemmende Wirkung anf Amylase ausüben, so besteht keine Schwierigkeit, den Gehalt dieses Ferments exakt $z u$ messen. Die Bestimmung wurde nach Woh lgem ut hscher 30 MinutenMethode mit $0,1 \%$ iger Stärkelösung (Ka hlbaum) ausgeführt. Dic Ergebnisse sind im folgenden verzeichnet (Tabelle I).

Aus der Tabelle ersieht man, dass Steigerung der Harnamylase mit der der Blutamylase Hand in Hand gcht. Die höchste Zahl der Harnamylase beträgt $4000 \mathrm{E}$. (Versuch 2), wobei die Blutamylase bis auf 1000 ansteigt. Auch gibt es unter den Versuchstieren einige, bei welchen Pilocarpininjektion keine Steigerung der Blutamylase und folglich auch keine der Harnamylase zur Folge hatte. Dies waren meist diejenigen 'Tiere, die keine genügende Menge Pilocarpin bekommen hatten.

Ferner haben wir an Hunden denselben Versuch ausgeführt, und zwar an normalen sowie an Hunden mit Ductusfistel (Tabelle II).

Das Versuchsergebnis bei Hunden, welche keine Ductusfistel haben, ist dasselbe wie bei Kaninchen. Hunde, welche Ductusfistel hatten, bekamen geringe Zunahme der Blut- und Harnamylase. Aus den Versuchen erkennt man, dass dic Amylase auf dem Wege über den Ductus thoracicus ins Blut getrieben wird und aus dem Blut durch die Nieren im Harn erscheint. Das steht wohl mit dem Versuche von Kumagai und Osato" im Einklang.

\section{Pepsin.}

Bräcke fand zuerst im normalen Harn Pepsin, was von Grüt\%ne $\mathrm{r}^{10)}$ bestätigt wurde. Fried berge $\mathrm{r}^{11)}$ fand das Parallelgehen des Harnpepsins mit der Menge der Sekrction des Magens. Mat thes ${ }^{12}$ wies nach, 
II. Xamamoto

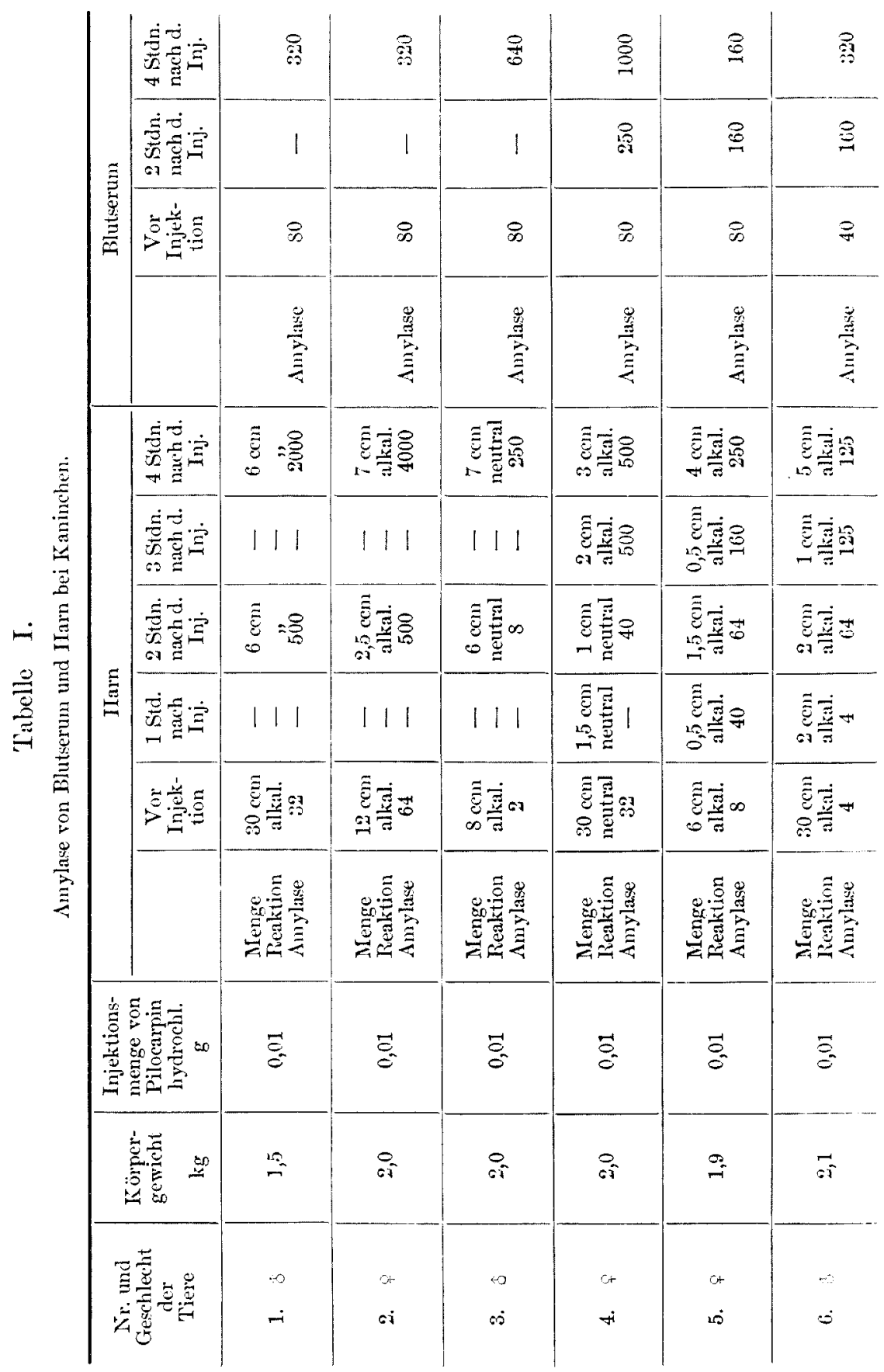




\begin{tabular}{|c|c|c|c|c|c|c|c|}
\hline 周 & $\underset{8}{8}$ & 1 & 1 & $\stackrel{19}{-9}$ & ใิ & 1 & $\begin{array}{l}19 \\
99\end{array}$ \\
\hline$\stackrel{8}{\circ}$ & : & 1 & 1 & 1 & 1 & $\stackrel{8}{\infty}$ & $\vec{త}$ \\
\hline 왁 & 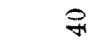 & 1 & 1 & 9 & \pm & 웍 & 9 \\
\hline$\underset{z}{\stackrel{0}{3}}$ & 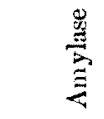 & 1 & 1 & 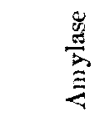 & 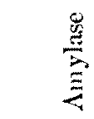 & 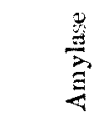 & 总 \\
\hline 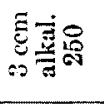 & 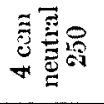 & 홇 & 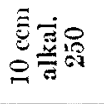 & 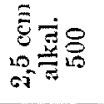 & 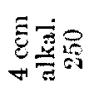 & 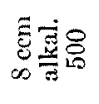 & 焉焉最 \\
\hline 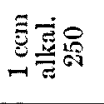 & 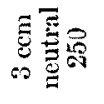 & 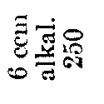 & 111 & $\begin{array}{l}\mathrm{D} \\
0\end{array}$ & 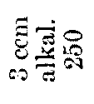 & 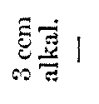 & 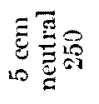 \\
\hline 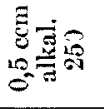 & 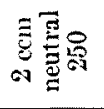 & 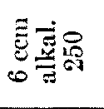 & 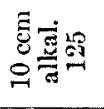 & 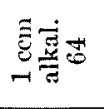 & 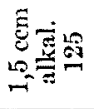 & 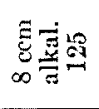 & 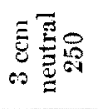 \\
\hline 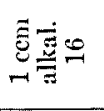 & $\underset{\bar{E}}{\tilde{E}}$ & 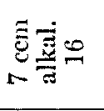 & 111 & 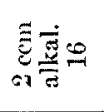 & 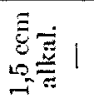 & 豆苛 & $\underset{E}{E}$ \\
\hline 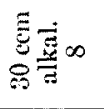 & 苞害 & 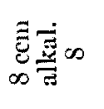 & 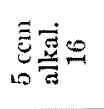 & 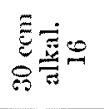 & 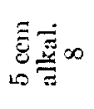 & 苞焉 & 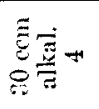 \\
\hline 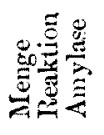 & 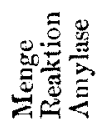 & 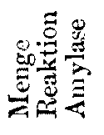 & 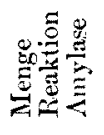 & 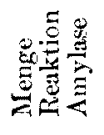 & 要焉 & 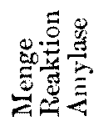 & 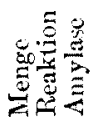 \\
\hline 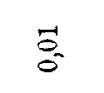 & $\overrightarrow{0}$ & $\stackrel{8}{8}$ & $\stackrel{\infty}{6}$ & $\vec{E}$ & 8 & $\vec{E}$ & $\vec{E}$ \\
\hline 8 & $\overrightarrow{\text { ET }}$ & $\stackrel{0}{-}$ & $\stackrel{10}{-1}$ & 8 & $\begin{array}{l}67 \\
61\end{array}$ & $\stackrel{\infty}{-}$ & $\overrightarrow{65}$ \\
\hline$\leftrightarrow$ & $\mathrm{OH}^{-}$ & ot & ot & 0 & $\cdots$ & 0 & + \\
\hline$\therefore$ & $\infty$ & $\dot{\sigma}^{\circ}$ & $\dot{\vec{\theta}}$ & $\rightleftarrows$ & $2 i$ & $\dot{s}$ & $\stackrel{+}{ \pm}$ \\
\hline
\end{tabular}




\section{Tabelle II.}

Amylase von Blutserum und ITarn bei Frunden mit Duetusfistel und normalen Hunden.

\begin{tabular}{|c|c|c|c|c|c|c|c|c|c|c|c|c|}
\hline \multirow{2}{*}{ 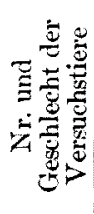 } & \multirow{2}{*}{ 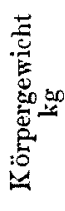 } & \multirow{2}{*}{ 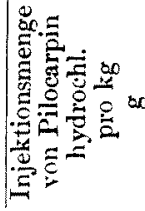 } & \multicolumn{6}{|c|}{ Harn } & \multicolumn{4}{|c|}{ Blutserum } \\
\hline & & & $\vec{b}$ & $p$ & 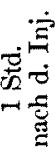 & 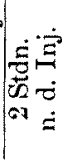 & 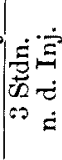 & 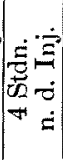 & 官 & 这 & 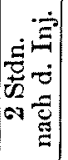 & 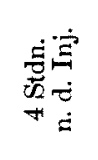 \\
\hline 1. & 9,8 & 0,01 & 1 & $\mathcal{2}$ & 2 & 2 & \multicolumn{2}{|c|}{ gestorben } & 64 & - & 125 & gestorben \\
\hline 2. 4 & 10,0 & 0,006 & 1 & 2 & - & 4 & \multicolumn{2}{|c|}{ gestorben } & 64 & - & 64 & gestorben \\
\hline 3. & 19,0 & 0,002 & 2 & 2 & 2 & 2 & - & - & 64 & 64 & 125 & 250 \\
\hline 4. & 20,0 & 0,004 & 4 & 4 & 4 & \multicolumn{2}{|c|}{ gestorben } & & 32 & 32 & 32 & gestorben \\
\hline 5. क & 19,0 & 0,004 & $\begin{array}{c}\text { olno } \\
\text { operation }\end{array}$ & 8 & 8 & 32 & - & 125 & 32 & 32 & 250 & 1250 \\
\hline 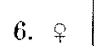 & 21,0 & 0,003 & $\begin{array}{c}\text { ohne } \\
\text { operation }\end{array}$ & 2 & 2 & 64 & 250 & - & 32 & 32 & 500 & 1250 \\
\hline
\end{tabular}

dass Harnpepsin aus dem Magen stammt, da es bei Hunden nach Totalexstirpation des Magens aus dem Harn verschwindet und auch bei Pepsinfütterung wieder crscheint; wird der Magen nur ausgeschaltet, so wird es resorbiert und erscheint im Harn. Nach Ellinge ${ }^{13)}$ enthält der Harn neben Pepsin auch Propepsin; intravenös eingeführtes Pepsin und Propepsin sollen im Harn unverändert ausgeschieden werden, subkutane und stomachale Einverleibung dagegen keine Vermehrung des Harnpepsins bewirken, nach $\mathrm{Fu} \mathrm{ld}^{14}$ ist dagegen Harmpepsin ausschliesslich Zymogen. Im Serum ist Pepsin noch nicht mit Sicherheit nachgewiesen worden. Ausser dem Pepsin enthalten sowohl Blut wie auch Harn eine hemmende Wirkung dem Pepsin gegenüber, das sogenannte Antipepsin. Da wir fanden, dass sich die Harnamylase auf Pilocarpininjektion hin stark steigert, so haben wir die Wirkung des Pilocarpins auf Harnpepsin untersucht. Für diesen Versuch sind wegen äusserer Umstïnde ausschliesslich Kaninchen verwendet worden, obwohl die bisherigen Untersuchungen des Harnpepsins hauptsächlich an Carnivoren ausgef ührt worden sind.

Methodisches: Für die Pepsinbestimmung wurde die Methode ron Gross ${ }^{15}$ angewendet ; 0,1 ójige salzsaure Caseinlösung wurde mit Caseinum purissimum nach $\mathrm{Ham} \mathrm{mar-}$ sten hergestellt und fïr die Fïllung 20\%:́ige Lösung von essigsaurem Natrium verwandt. 
Eine Reihe von Reagenzgläschen wurde mit fallenden Mengen mit Salzsïure angesiutuerten Harns oder Serums beschickt. Jedem Glïschen wurde $1 \mathrm{ccm}$ der Caseinlösung zugefügt und die ganze Reihe 30 Minuten lang ins $W$ asserbad bei $38^{\circ} \mathrm{C}$ gestellt. Darauf wurden einige Tropfen ron Natriumacetat jedem Reagenzglïschen zugesetzt, um unrerdaut gebliebenes Casein nachzuweisen. Für Antipepsin wurde eine Reihe ron Reagenzglïschen mit je $\mathbf{2}$ fach lösender Dose von Pepsin beschickt, darauf fallende Mengen IIarn oder Serum zugesetzt, alsdann 30 Minuten im Wasserbad von $38^{\circ} \mathrm{C}$ stehen gelassen, endlich zu jedem Reagenzglïschen $1 \mathrm{ccm}$ der Caseinlösung zugesetzt und eine Stunde lang im Wasserbad bei $38^{\circ}$ gelassen.

Als Pepsineinheit nahmen wir diejenige Menge, die noch imstande ist, $1 \mathrm{ccm}$ Caseinlösung in 30 Minuten ganz zu verdauell, sodass auf Zusatz von Natriumacetat keine Trübung eintrat. Hieraus wurde die Zahl der Einheit für $1 \mathrm{ccm}$ der zu untersuchenden Flüssigkeit berechnet. Dieselbe Berechnung wurde für die antipeptische Kraft angewandt. Das Versuchsresultat sei im folgenden tabellarisch wiedergegeben.

Tabelle III.

Pepsin und Antipepsin von Blutserum u. Harn bei Kaninchen.

\begin{tabular}{|c|c|c|c|c|c|c|c|c|c|}
\hline \multirow[b]{2}{*}{ 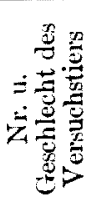 } & \multirow{2}{*}{ 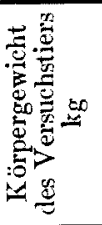 } & \multirow{2}{*}{ 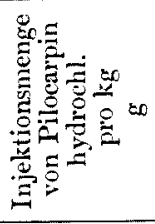 } & \multirow[b]{2}{*}{ 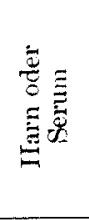 } & \multicolumn{3}{|c|}{ Pepsin } & \multicolumn{3}{|c|}{ Antipepsin } \\
\hline & & & & 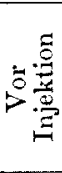 & 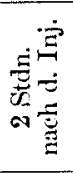 & 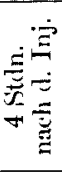 & $p \frac{\frac{g}{g}}{\frac{E}{g}}$ & 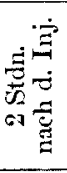 & 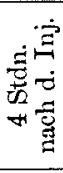 \\
\hline 1. $\frac{?}{\mathrm{~T}}$ & 1,8 & 0,01 & Harn & 2 & $(-)$ & $(-)$ & 16000 & 8 & 4 \\
\hline 2. j & 2,0 & 0,01 & Harn & 2 & $(-)$ & $(-)$ & 1000 & 4 & 2 \\
\hline 8.3 & 1,7 & 0,01 & Harn & 2 & $(-)$ & $(-)$ & 500 & - & 2 \\
\hline 4. 6 & $1, \overline{5}$ & 0,01 & $\begin{array}{l}\text { Harn } \\
\text { Serum }\end{array}$ & $\begin{array}{l}(-) \\
(-)\end{array}$ & $\begin{array}{l}(-) \\
(-)\end{array}$ & $(-)$ & $\begin{array}{r}16 \\
1250\end{array}$ & $\frac{2}{-}$ & $\begin{array}{l}2 \\
2\end{array}$ \\
\hline 5. ? & 2,0 & 0,01 & $\begin{array}{l}\text { Harn } \\
\text { Serum }\end{array}$ & $(-)$ & $(-)$ & $(-)$ & $\begin{array}{l}250 \\
320\end{array}$ & $(-)$ & $(-)$ \\
\hline 6. 0 & 2,0 & 0,01 & $\begin{array}{l}\text { Harn } \\
\text { Serum }\end{array}$ & $(-)$ & $(-)$ & $(-)$ & $\begin{array}{r}125 \\
1250\end{array}$ & 4 & $\begin{array}{c}1 \\
64\end{array}$ \\
\hline
\end{tabular}

Wie man aus dieser Tabelle sieht, enthält der Harn mancher Kaninchen eine ganz geringe Menge von Pepsin, während es bei den anderen garnicht nachweisbar ist. Auch bei denjenigen Tieren, in deren Harn Pep- 
sin nachweisbar war, verschwand Harmpepsin nach Injektion von Pilocarpin vollständig. Bei den Tieren, bei welchen Pepsin im Harn von vornherein garnicht nach weisbar war, erschien kein Harnpepsin, auch nicht auf Pilocarpininjektion hin. Im Scrum konnten wir bei sämtlichen Tieren gar kein Pepsin nachweisen. Was das Antipepsin anbetrifft, so konnte es immer, sowohl im Serum als anch im Harn, nachgewiesen werden. Die antipeptische Kraft des Serums schwankt nicht so sehr : sie betrügt zwischen 32 und 125 Einheiten. Nach Pilocarpininjektion nimmt diese Wirkung rasch $a b$, oft bis auf eine Einheit. Die antipeptische Wirkung des Harns war bei einem Tiere sehr stark, z. B. Nr. 1 hatte 16000 Einheiten, bei den anderen war sie nicht so stark. Das Harnantipepsin geht auch nach Pilocarpininjektion rasch herunter. Da das Wesen der antipeptischen Wirkung noch nicht klar gestellt ist, so können wir keine gute Erklärung für diese Erscheinung beibringen.

Durchsieht man die Literatur über den Einfluss des Pilocarpins auf die Sekretion des Magensafts, insbesondere des Pepsins, so findet man nur widersprechende Angaben. Nach Amantea ${ }^{16)}$ wird die Sekretion des Magensafts durch Pilocarpin angeregt, aber im Hungerzustand herabgesetzt. Hein $z^{17)}$ gibt an, dass er kein eindeutiges Resultat erzielt habe. Nach der Untersuchung von Mitrovitch ${ }^{18}$ vermindert sich der Pepsingehalt des Magensafts auf Pilocarpininjektion hin. Diese nicht übereinstimmenden Resultate kommen wahrscheinlich von den verschiedenen angewandten Dosen her. Es ist höchstwahrscheinlich, dass die von uns angewandten Pilocarpindose die Pepsinsekretion der Magenschleimhaut hemmt, so dass es auch das Harnpepsin vermindert.

\section{Trypsin.}

Über das Vorkommen des proteolytischen Ferments Trypsin im Harn gibt es nur widersprechende Angaben. Die älteren Angaben von Geh ri g ${ }^{193}$ und Bendersky, ${ }^{20)}$ dass dieses Ferment im Harn vorhanden ist, sind von $\mathrm{Le}^{21}$ widerlegt. Hoffmann ${ }^{20)}$ fand im normalen Harn niemals Trypsin, aber nach Unterbindung des Ductus pancreaticus fand er bei einem Kaninchen reichliche Menge von Trypsin in Harn. Catheart $t^{23)}$ komnte mit Casein Trypsin aus dem Harn ausfällen. Grützner ${ }^{2 q)}$ fand Trypsin nur dann im Harn, wenn der Pankreassaft vom Darm abgeschlossen war, sonst niemals. Die meisten Autoren haben sich dieser Ansicht, dass Trypsin im normalen Harn nicht vorkommt, angeschlossen. Dagegen komnten Hedin und $M$ asa $i^{-5 j}$ ans dem Harn proteolytische Fermente ausfïllen. 
1920 konnte Hedi in ${ }^{20)}$ das proteolytische Ferment im Harn nachweisen, indem er den Harn gegen das Leitungswasser dialysierte. Diese widersprechenden Angaben über das Vorkommen des Trypsins im Harn kommen meiner Meinung nach daher, dass der Urin antitryptische Wirkung hat. Osato $\left.{ }^{2 i}\right)$ hat gefunden, dass pilocarpinvergiftete Ticre grosse Mengen von Trypsin und Lipase im Blut haben, welche ans dem Pankreas stammen. Wir haben num untersucht, ob dieses gesteigerte Trypsin im Blut in den Urin übergeht.

Anfangs haben wir uns der F uld-G ross'schen Methode bedient. Damit komnten wir keine Spur von 'Trypsin im Harn, weder bei normalen noch bei mit Pilocarpin vergifteten Ticren nachweisen. Deshalb haben wir cinen anderen Weg eingeschlagen; es musste erst die antitryptische Wirkung bescitigt werden. Aceton, welches von S. Y a mak a w a ${ }^{28}$ zur Beseitigung der hemmenden Wirkung des Serums und von Osato mit Erfolg für den Nachweis des Trypsins im Serum benutzt wurde, ward verwendet.

Methodi-ches: Einer bestimmten MIenge von Urin, welche zur Aktivierung des Trypcinogens mit einigen Tropfen $22 \%$ óiger $\mathrm{CaCl}_{2}$-Lösung versetzt worden, wurde in Verhältnis ron $1: 0,7$ Aceton zugesetzt und dies geschiittelt; dann wurde es in einen dialysierenden Beutel getan. Es wurde gegen destilliertes Wasser, welches vorher mit Tuluol geschiittelt worden war, 5 Stunden lang dialysiert. $Z$ wei cem des so behandelten Urins wurden mit 1 $\mathrm{ccm} 1 \%$ iger alkalischer Caseinlösung rersetzt; das Gemisch wurde nach Zusatz einiger Tropfen Tuluol 48 Stunden lang in den Brutschrank bei $38^{\circ} \mathrm{C}$ gestellt und dann mit Gerbsilurelösung, welche auf $1000 \mathrm{ccm}$ Wasser $100 \mathrm{~g}$ Gerbsiure, $50 \mathrm{~g}$ Kochsal $\mathrm{c}, 50 \mathrm{~g}$ Natriumacetat und $50 \mathrm{ccm}$ Eisessig enthielt, enteiweisst. Der N-Gehalt des so gewonnenen Filtrats wurde nach Mikrokjeldahl bestinmt.

Zur Kontrolle wurde mit Urin, welcher auf dieselbe Weise behandelt und bei $100^{\circ} \mathrm{C}$ erhitat war, cbenso verfahren. Das Resultat ersieht man aus Folgendem.

Tabelle IV.

Trypsin von Blutserum und IFarn bei Kaninchen.

\begin{tabular}{|c|c|c|c|c|c|c|c|c|}
\hline \multirow[b]{2}{*}{ 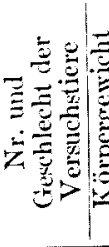 } & \multirow[b]{2}{*}{ 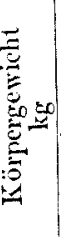 } & \multirow[b]{2}{*}{ 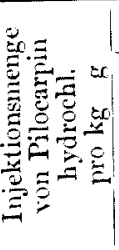 } & \multicolumn{3}{|c|}{ IIarn } & \multicolumn{3}{|c|}{ Blutserum } \\
\hline & & & 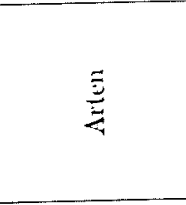 & 公 & $\begin{array}{l}3 \\
0\end{array}$ & 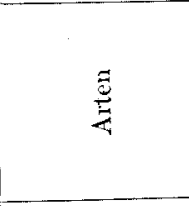 & 乙 & 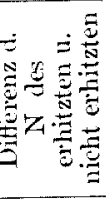 \\
\hline 1. $\mathrm{o}$ & 1,8 & 0,007 & 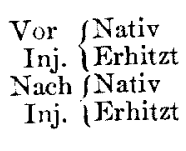 & $\begin{array}{l}0,020 \\
0,017 \\
0,036 \\
0,022\end{array}$ & 0,014 & $\begin{array}{l}\text { Vor ( Nativ } \\
\text { Inj. I Erhitzt } \\
\text { Nach / Nativ } \\
\text { Inj. I Erhitzt }\end{array}$ & $\begin{array}{l}0,025 \\
0,022 \\
0,129 \\
0,020\end{array}$ & $\begin{array}{l}0,008 \\
0,109\end{array}$ \\
\hline
\end{tabular}




\begin{tabular}{|c|c|c|c|c|c|c|c|c|}
\hline \multirow[b]{2}{*}{ 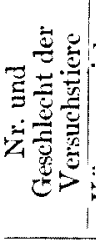 } & \multirow[b]{2}{*}{ 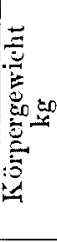 } & \multirow[b]{2}{*}{ 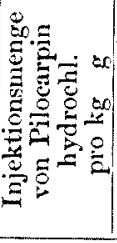 } & \multicolumn{3}{|c|}{ Harn } & \multicolumn{3}{|c|}{ Blutserum } \\
\hline & & & $\stackrel{5}{\stackrel{5}{z}}$ & 乙 & 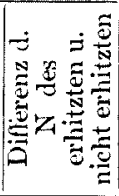 & $\stackrel{\Xi}{\Xi}$ & 乙 & 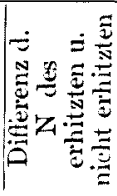 \\
\hline 2. 0 & 2,0 & 0,007 & $\begin{aligned} & \text { Vor } \text { Nativ } \\
& \text { Inj. I Frhitzt } \\
& \text { Nach I Natir } \\
& \text { Inj. I Erhitzt }\end{aligned}$ & $\begin{array}{l}0,025 \\
0,005 \\
0,025 \\
0,005\end{array}$ & $\begin{array}{l}0,022 \\
0,023\end{array}$ & 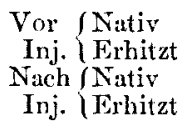 & $\begin{array}{l}0,025 \\
0,022 \\
0,042 \\
0,014\end{array}$ & $\begin{array}{l}0,003 \\
0,028\end{array}$ \\
\hline$\therefore 9$ & 2,2 & 0,006 & 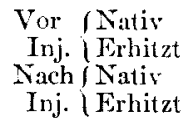 & $\begin{array}{l}0,014 \\
0,011 \\
0,046 \\
0,014\end{array}$ & $\begin{array}{l}0,003 \\
0,082\end{array}$ & & & \\
\hline 4. 8 & 2,1 & 0,006 & $\begin{array}{l}\text { Vor \{ Nativ } \\
\text { Inj. Y Frhitzt } \\
\text { Nach N Nativ } \\
\text { Inj. I Frhitzt }\end{array}$ & $\begin{array}{l}0,025 \\
0,022 \\
0,021 \\
0,003\end{array}$ & $\begin{array}{l}0,003 \\
0,018\end{array}$ & & & \\
\hline 5. 3 & 1,6 & 0,000 & 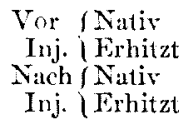 & $\begin{array}{l}0,011 \\
0,0 \\
0,034 \\
0,0\end{array}$ & $\begin{array}{l}0,011 \\
0,034\end{array}$ & & & \\
\hline (i. 9 & 2,0 & 0,01 & $\begin{array}{l}\text { Vor \{ Nativ } \\
\text { Inj. \{ Frhitzt } \\
\text { Nach \{ Nativ } \\
\text { Inj. \{ Erhitzt }\end{array}$ & $\begin{array}{l}0,008 \\
0,008 \\
0,022 \\
0,003\end{array}$ & $\begin{array}{l}0,0 \\
0,019\end{array}$ & & & \\
\hline 3 & 1,8 & 0,004 & $\begin{array}{l}\text { Yor \{ Nativ } \\
\text { Inj. \{ Erhitat } \\
\text { Nach Y Nativ } \\
\text { Inj. ( Erhitzt }\end{array}$ & $\begin{array}{l}0,014 \\
0,008 \\
0,020 \\
0,011\end{array}$ & $\begin{array}{l}0,006 \\
0,009\end{array}$ & & & \\
\hline 8. 9 & 2,0 & 0,006 & $\begin{aligned} \text { Vor }\{\text { Nativ } \\
\text { Inj. }\left\{\begin{array}{l}\text { Frhitzt } \\
\text { Nach }\end{array} \text { Nativ }\right. \\
\text { Inj. Y Erhitzt }\end{aligned}$ & $\begin{array}{l}0,007 \\
0,003 \\
0,020 \\
0,011\end{array}$ & $\begin{array}{l}0,004 \\
0,009\end{array}$ & & & \\
\hline
\end{tabular}

Wie man aus der Tabelle sicht, hat der normale Kaninchenharn fast gar keine proteolytische Wirkuug, aber der nach Pilocarpininjektion entnommene Urin zeigt eine zwar geringfügige, aber unverkennbare proteolytische Wirkung. Vom Serum haben wir nur zwei Fälle untersucht ; der eine zeigte nach Pilocarpininjektion eine sehr kräftige tryptische Wirkung auf Cascin, der andere nur eine sehr schwache. 


\section{Lipase.}

Zuerst find $T$ a n $f_{\text {a }}$ n $\mathrm{i}^{\text {an }}$ in Harn geringe Spuren Lipase ; nach Gewlett ${ }^{302}$ soll sie nach Schïdigung des Pankreas in den Harn ïbergehen. Auch bei Nicrenläsion soll sic in dem Harn vermehrt gefunden werden. Osato fand, dass Blut- und Lymphlipase bei Pilocarpininjektion sehr gesteigert wird. Deshalb ist zu erwarten, dass die dabei vermehrte Lipase auch in den Harn übergeht.

Was dic Methodik anbelangt, so ist die Bestimmung ler Lipase nach Rona und Michacli $\mathrm{s}^{31}$ ausgeführt worden. Das Resultat ist in folgender Tabelle und Figur dargestellt.

Tabelle V.

Lipase von Blutserum und Ifarn bi Kaninchen.

\begin{tabular}{|c|c|c|c|c|c|c|c|c|c|c|c|c|c|}
\hline \multirow{3}{*}{\multicolumn{2}{|c|}{ 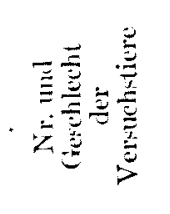 }} & \multirow{3}{*}{ 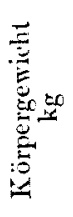 } & \multirow{3}{*}{ 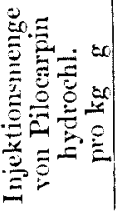 } & \multirow{3}{*}{ 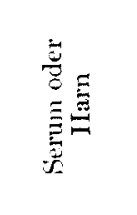 } & \multicolumn{9}{|c|}{ Tropfenzabl } \\
\hline & & & & & \multicolumn{3}{|c|}{$\begin{array}{l}\text { Vor d. } \\
\text { Injektoin }\end{array}$} & \multicolumn{3}{|c|}{$\begin{array}{l}2 \text { Stdn. } \\
\text { nach d. Inj. }\end{array}$} & \multicolumn{3}{|c|}{$\begin{array}{c}4 \mathrm{Stdn} . \\
\text { nach d. Inj. }\end{array}$} \\
\hline & & & & & $10^{\prime}$ & $20^{\prime}$ & $30^{\prime}$ & $10^{\prime}$ & $20^{\prime}$ & $30^{\prime}$ & $10^{\prime}$ & $20^{\prime}$ & $30^{\prime}$ \\
\hline \multirow{2}{*}{$\stackrel{\Xi}{\Xi}$} & 1. & 10,0 & $0,0]$ & $\begin{array}{ll}\text { Iarn } & 2,0 \\
\text { Serum } & 0,5\end{array}$ & $\begin{array}{l}104 \\
100\end{array}$ & $\begin{array}{l}95 \\
91\end{array}$ & $\begin{array}{l}91 \\
87\end{array}$ & $\begin{array}{l}95 \\
92\end{array}$ & $\begin{array}{l}84 \\
83\end{array}$ & $\begin{array}{l}53 \\
52\end{array}$ & $\begin{array}{l}90 \\
85\end{array}$ & $\begin{array}{l}84 \\
77\end{array}$ & $\begin{array}{l}81 \\
76\end{array}$ \\
\hline & 2. P & 20,0 & 0,004 & $\begin{array}{lr}\text { Iarn } & 2,0 \\
\text { Serum } & 0,5\end{array}$ & $\begin{array}{l}105 \\
103\end{array}$ & $\begin{array}{l}96 \\
94\end{array}$ & $\begin{array}{l}93 \\
90\end{array}$ & $\begin{array}{l}97 \\
95\end{array}$ & $\begin{array}{l}90 \\
88\end{array}$ & $\begin{array}{l}85 \\
85\end{array}$ & $\begin{array}{l}95 \\
88\end{array}$ & $\begin{array}{l}87 \\
80\end{array}$ & $\begin{array}{l}84 \\
79\end{array}$ \\
\hline \multirow{5}{*}{ 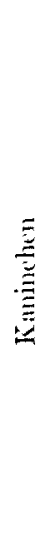 } & 1. ? & $1, \mathrm{~S}$ & 0,008 & $\begin{array}{ll}\text { Iarn } & 2,0 \\
\text { Serum } & 0,5\end{array}$ & $\begin{array}{l}98 \\
97\end{array}$ & $\begin{array}{l}92 \\
90\end{array}$ & $\begin{array}{l}88 \\
86\end{array}$ & $\begin{array}{l}90 \\
92\end{array}$ & $\begin{array}{l}53 \\
83\end{array}$ & $\begin{array}{l}82 \\
82\end{array}$ & $\begin{array}{l}84 \\
86\end{array}$ & $\begin{array}{l}78 \\
81\end{array}$ & $\begin{array}{l}77 \\
81\end{array}$ \\
\hline & 2. $\mathrm{े}$ & 2,0 & 0,01 & $\begin{array}{ll}\text { Iarn } & 2,0 \\
\text { Serum } & 0,5\end{array}$ & $\begin{array}{l}99 \\
97\end{array}$ & $\begin{array}{l}93 \\
91\end{array}$ & $\begin{array}{l}88 \\
87\end{array}$ & $\begin{array}{l}94 \\
92\end{array}$ & $\begin{array}{l}89 \\
84\end{array}$ & $\begin{array}{l}86 \\
80\end{array}$ & $\begin{array}{l}82 \\
85\end{array}$ & $\begin{array}{l}76 \\
\text { so }\end{array}$ & $\begin{array}{l}75 \\
\text { so }\end{array}$ \\
\hline & 3. $\hat{\theta}$ & 2,2 & 0,01 & $\begin{array}{ll}\text { ILarn } & 2,0 \\
\text { Serum } & 0,5\end{array}$ & $\begin{array}{l}98 \\
96\end{array}$ & $\begin{array}{l}91 \\
90\end{array}$ & $\begin{array}{l}89 \\
85\end{array}$ & $\begin{array}{l}91 \\
91\end{array}$ & $\begin{array}{l}84 \\
82\end{array}$ & $\begin{array}{l}83 \\
82\end{array}$ & $\begin{array}{l}85 \\
86\end{array}$ & $\begin{array}{l}79 \\
80\end{array}$ & $\begin{array}{l}78 \\
80\end{array}$ \\
\hline & 4. 3 & 1,6 & 0,01 & $\begin{array}{ll}\text { IIarn } & 2,0 \\
\text { Serum } & 0,5\end{array}$ & $\begin{array}{l}99 \\
96\end{array}$ & $\begin{array}{l}98 \\
89\end{array}$ & $\begin{array}{l}87 \\
85\end{array}$ & $\begin{array}{l}91 \\
90\end{array}$ & $\begin{array}{l}84 \\
82\end{array}$ & $\begin{array}{l}\$ 2 \\
\$ 1\end{array}$ & $\begin{array}{l}85 \\
85\end{array}$ & $\begin{array}{l}79 \\
50\end{array}$ & $\begin{array}{l}77 \\
78\end{array}$ \\
\hline & 5. 욱 & 2,1 & 0,01 & $\begin{array}{ll}\text { Iarn } & 2,0 \\
\text { Serum } & 0,5\end{array}$ & $\begin{array}{r}100 \\
98\end{array}$ & $\begin{array}{l}95 \\
91\end{array}$ & $\begin{array}{l}87 \\
86\end{array}$ & $\begin{array}{l}95 \\
91\end{array}$ & $\begin{array}{l}88 \\
82\end{array}$ & $\begin{array}{l}86 \\
80\end{array}$ & $\begin{array}{l}84 \\
86\end{array}$ & $\begin{array}{l}77 \\
80\end{array}$ & $\begin{array}{l}76 \\
77\end{array}$ \\
\hline
\end{tabular}

Senerkung: Tropfenzahl d. ges:ittigten Tributyrinlüsung 116; die der Aq. dest. 74. Tropfenzahl d. Gemisches vor Digestion 113 oder 112. 
Fig. 1 (Ilund 1).

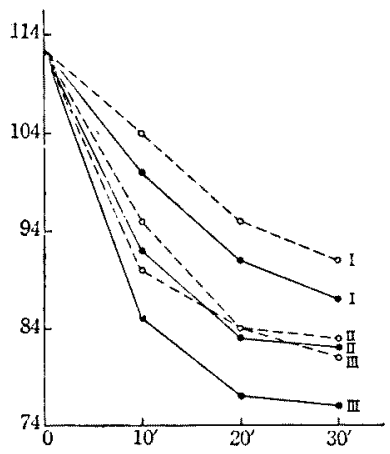

Fig. 2 (Kaninchen 1$)$.

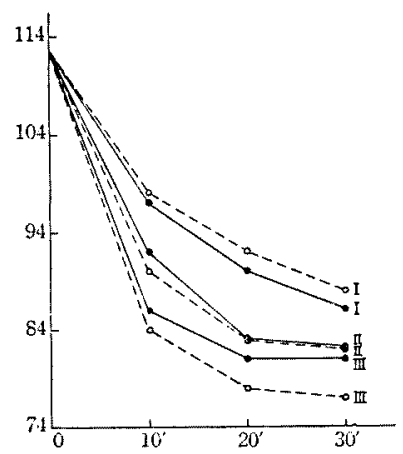

Restimmung der Lipase nach Rona und Michaelis.

Serum resp. II arn

Rindergalle

Phosphatmischung

Gesïttigte Tributyrinlösung

$$
\left.\begin{array}{r}
0,5 \text { resp. } 2,0 \mathrm{cem} \\
0,1 \mathrm{~cm} \\
2,0 \mathrm{~cm} \\
\Lambda d .50,0 \mathrm{~cm}
\end{array}\right) \text { in } 87^{\circ} \mathrm{C} .
$$

Ordinate: Tropfenzahl.

Abszisse: Versuchsdauer in Minuten.

- - Lipase des Blutserums (I, II und III vor und 2 resp. 4 Stunden nuch Pilocarpininjektion).

- - -o Lipase des Harns.

So ist unsere Erwartung bestätigt worden ; nämlich durch Pilocarpin wird die Blutlipase verstïkt, infolgedessen die Harnlipase auch.

\section{Zusammenfassung.}

Durch subkutane Injektion einer grossen Menge Pilocarpins wird die Harnamylase vermehrt; die Vermehrung geht mit der der Blutamylase parallel. Im normalen Kaninchenharn ist tryptisches Ferment kaum nachweisbar, im Harn pilocarpinvergifteter Kaninchen ist es deutlich nachweisbar. Auch die Lipase des Harns wird durch Pilocarpininjektion gesteigert. Pepsin ist im Kaninchenharn bald nachweisbar, bald nicht: Ist es vorhanden, so verschwindet es durch Injektion des Pilocarpins. Die antipeptische Wirkung sowohl des Serums wie anch des Harns wird durch Pilocarpininjelition vermindert.

\section{Literatur.}

(1) T. Wohlgemuth und Y. Noguchi, Berl. klin. Wochenschr., 1912, 1069.

(2) A chard und Cle rc, Arch. de Méd. experiment. d' Anat. Pathol, 1905, 14, 809.

(3) Loeper und Fiçai, Arch. de Méd. experiment. d' Anat. Pathol., 1907, 19, 722. 
(4) Osato, Tohoku Journ. of Exp. Med., 1920, 1, 1.

(5) M asumizu, Tohoku Journ. of Exp. Med., 1920, 5, 1.

(6) Tsunoda, Fukuoka Ikadaigaku Zasshi, 1918, 10, 393.

(7) Wohlgemuth, Biochem. Zeitschr., 1908, 9, 1.

(S) Kumagai und Osa to, Tohoku Journ. of Exp. Med, 1920, 1, 153.

(9) Brücke, zit. nach Oppen heimer's Fermente und ihre Wirkungen. Bd. II, 4. Auflige, Leipzig 1913, S. 583 .

(10) Gritzner, zit. nach Op penheimer's Fermente und ihre Wirkungen. Bd. II, 4. Autlage Leipzig 1913, S. 523.

(11) Friedberger, M al y's Jahrb., 1900, 30, 335.

(12) Mathes, Arch. f. exp. Pathol. und Pharmakol, 1903, 49, 107.

(13) Ellinger, Dtsch. Arch. f. klin. Med., 1910, 99, 221.

(14) Fuld, Zeitschr. f. experin. Pathol, 1912, 10, 248.

(15) Gross, Berl. klin. Wochenschr., 1908, 643.

(16) A mantea, zit. in Berichte über die gesamte Pathologie und exp. Pharmakologie, $1925,30,727$.

(17) Ileinz, Arch. f. Verdauungskrankh., 1924, 32, 219.

(18) Mitrovitch, Cpt. rend. soc. Biol, 1926, 94, 221.

(19) Gehrig, Pfliger's Arch., 18s6, 38, 35.

(20) Bendersky, Virchow's Arch., 1890, 121, 554.

(21) Leo, Pflüger's Arch., 1885, 37, 223.

(22) Hoffm an n, Pflüger's Arch., 1887, 41, 148.

(23) Cathcart, Journ. of Physiol, 1903, 31, 497.

(24) Grïtzner, Deutsche med. Wochenschr., 1891, 1.

(25) Hedin und Masai, Ho p pe-Se y ler's Zeitschr. f. physiol. Chem., 1917, 100, 263.

(26) Hedin und Masa i, Ho p pe-Sey ler's Zeitschr. f. physiol. Chem., 1920, 112, 252.

(47) Osato, Tohoku Journ. of Exp. Med., 1922, 2, 514.

(2S) Yamakawa, Journ. of exp. Med., 1918, 27, 689.

(29) Tanfani, zit. nach Op penheimer's Fermente und ihre Wirkungen $\mathbf{B d}$. I, 4. Autlage, Leipzig 1913, S. 164.

(30) Gewlett, Journ. med. Research, 1904, 11, 377.

(31) Ron and M ichael is, Biochem. Zeitschr., 1911, 31, 345. 